\title{
Sistem Informasi Pengarsipan Surat Masuk dan Surat Keluar Pada Dinas Tenaga Kerja dan Transmigrasi Kabupaten Musi Banyuasin
}

\author{
Rahayu Amalia ${ }^{1}$, Nurul Huda ${ }^{2, *}$ \\ ${ }^{1}$ Ilmu Komputer, Sistem Informasi, Universitas Bina Darma, Palembang, Indonesia \\ ${ }^{2}$ Ilmu Komputer, Teknik Informatika, Universitas Bina Darma, Palembang, Indonesia \\ Email: ${ }^{1}$ rahayu_amalia@binadarma.ac.id, ${ }^{2,}{ }^{*}$ urul_huda@binadarma.ac.id \\ Email Penulis Korespondensi: nurul_huda@binadarma.ac.id
}

\begin{abstract}
Abstrak-Dalam suatu instansi atau perusahaan surat merupakan salah satu media komunikasi yang sangat penting. Surat tersebut berupa surat masuk dan surat keluar. Pada Dinas Tenaga Kerja dan Transmigrasi Kabupaten Banyuasin ini dalam pengelolaan surat masuk dan surat keluar saat ini masih dilakukan secara manual mulai dari pembuatan, penyimpanan, dokumentasi, hingga verifikasi surat, semua di lakukan secara manual sehingga mengakibatkan tidak efektif dan efisien baik tenaga, waktu maupun biaya. Sistem Informasi Pengarsipan Surat dapat menjadi solusi atas masalah tersebut. Metodologi yang digunakan untuk merancang sistem informasi ini adalah dengan menggunakan metode RAD (Rapid Application Development) dan program yang dihasilkan dalam sistem ini adalah Sistem Informasi Pengarsipan Surat Masuk dan Surat Keluar pada Dinas Tenaga Kerja dan Transmigrasi Kabupaten Musi Banyuasin dengan menggunakan PHP sebagai bahasa pemrograman dan MySQL sebagai basis datanya.
\end{abstract}

Kata Kunci: Sistem Informasi, Surat, RAD, Pemrogramman PHP, Database MySQL

\begin{abstract}
In an agency or company a letter is one of the most important communication media. The letter is in the form of incoming and outgoing letters. At the Banyuasin Regency Manpower and Transmigration Office, management of incoming and outgoing letters is still done manually starting from making, storing, documenting, to verifying letters, all done manually so as to result in ineffective and inefficient energy, time and cost. Letter Filing Information System can be a solution to this problem. The methodology used to design this information system is to use the RAD (Rapid Application Development) method and the program produced in this system is the Information System for Filing Incoming and Outgoing Letters at the Manpower and Transmigration Office of Musi Banyuasin Regency using PHP as a programming language and MySQL as the database.
\end{abstract}

Keywords: Information Systems, Letters, RAD, PHP Programming, MySQL Database

\section{PENDAHULUAN}

Surat merupakan alat komunikasi tertulis yang berasal dari satu pihak dan ditujukan kepihak lain [1]. Dinas Tenaga Kerja dan Transmigrasi Kabupaten Musi Banyuasin yang pada saat ini prosedur pengolahan suratnya mulai dari membuat, menyimpanan, mendokumentasi, hingga memverifikasi surat, semua di lakukan secara manual. Surat masuk dan surat keluar hanya didokumentasikan pada pencatatan di buku, sedangkan untuk pengarsipan surat hanya berupa hardcopy [2]. Adapun permasalahan Pengelolahan surat masuk dan surat keluar yang terjadi pada saat ini diantaranya yaitu pencarian dokumen menjadi lebih lama dan juga sulit karena harus membuka terlebih dahulu data-data lama dan mencarinya satu persatu, proses disposisi yang masih menggunakan kertas dan setiap surat masuk dan surat keluar harus di fotocopy berulang-ulang untuk proses pengarsipan dan proses pendistribusian surat, serta hilang dan rusaknya dokumen surat[3]

Arsip merupakan rekaman kegiatan atau peristiwa yang dicatat, di rekam baik berupa tulisan, gambar, grafik sebagai bahan informasi dan komunikasi yang terekam dalam kertas maupun komputer[4]. Dalam suatu instansi Arsip merupakan salah satu sumber informasi yang sangat penting untuk menunjang proses kegiatan administrasi dan manajemen, seiring dengan berjalannya waktu dokumen arsip akan terus bertambah [5]. Oleh sebab itu perlu di rancang suatu sistem informasi pengarsipan surat yang terkomputerisasi sehingga dengan adanya sistem informasi pengarsipan surat ini diharapkan nantinya karyawan dapat mengelola surat dengan baik, memudahkan proses pengarsipan surat dan proses pencarian surat, sehingga pengelolahan surat dapat lebih efisien, cepat dan aman [6]. Sistem informasi ini dibuat dengan menggunakan bahasa pemrograman php yang merupakan proses penerjemah baris sumber menjadi kode mesin yang dimengerti komputer secara langsung pada saat baris kode dijalankan [7]. Sedangkan basisdata yang digunakan adalah My Sql dimana dalam penyimpanan datanya dalam bentuk tabel-tabel yang saling berhubungan [8] dan MY Sql juga dapat digunakan untuk membuat web dinamis [9].

\section{METODE PENELITIAN}

\subsection{Metode Pengembangan Sistem}

Metode RAD ( Rapid Application Development) merupakan metode yang digunakan dalam pengembangan sistem informasi pengarsipan surat ini. Adapun tahap-tahap dalam pengembangannya dapat dilihat pada gambar dibawah ini [10]: 


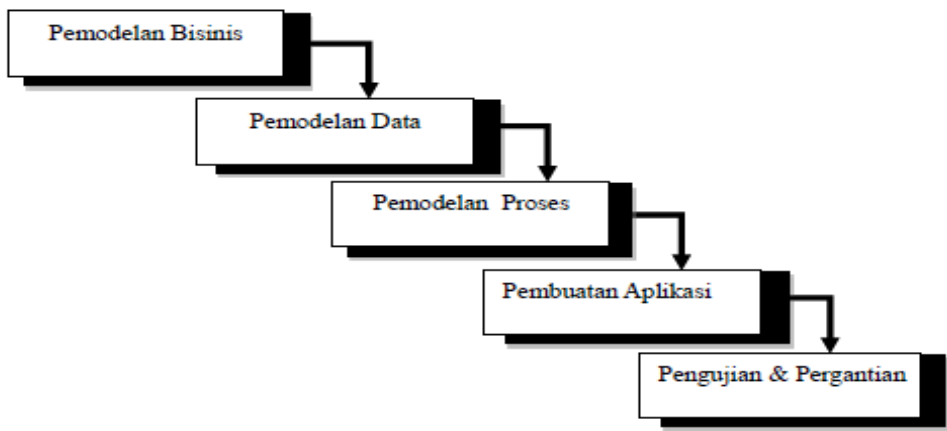

Gambar 1. Metode Pengembangan Sistem RAD

Proses Tahap-tahap pada RAD ( Rapid Application Development)

1. Pemodelan Bisnis

Pada tahap pemodelan bisnis ini melakukan pemodelan fungsi bisnis dimana untuk mengetahui informasi apa yang terkait dengan proses bisnis, surat apa saja yang harus di buat, siapa yang harus membuat surat serta alur pembuatan surat yang ada pada Dinas Tenaga Kerja dan Transmigrasi Kabupaten Musi Banyuasin.

2. Pemodelan Data

Tahap pemodelan data dimana yang dilakukan pada tahap ini yaitu mengetahui apa saja yang dibutuhkan berdasarkan pemodelan bisnis yang mendefinisikan atribut-atribut pada sistem informasi pengarsipan surat beserta relasinya. Pada tahap ini yang dilakukan adalah membuat disain usecase diagram dan class diagram yang menggambarkan sisitem yang akan dibuat.

3. Tahap pemodelan proses

Pada tahap pemodelan proses dilakukan implementasi fungsi sistem informasi Pengarsipan surat pada Dinas Tenaga Kerja dan Transmigrasi Kabupaten Musi Banyuasin dalam mengelola surat, yang sudah didefinisikan terkait dengan implementasi data.

4. Pembuatan Aplikasi

Pada tahap pembuatan aplikasi yang dilakukan yaitu mengimplementasikan pemodelan proses menjadi program. Pada tahap ini terdapat proses penerjemahan code-code program menggunakan bahasa pemrograman web.

5. Pengujian dan Pergantian

Menguji komponen-komponen pada sistem informasi pengarsipan surat yang telah dibuat

\subsection{Perancangan Sistem}

Perancangan sistem yang digunakan dalam pembuatan sistem administrasi pengarsipan ini yaitu menggunakan UML. Unified Modeling Language (UML) adalah sebuah standarisasi bahasa pemodelan untuk pembangunan perangkat lunak yang dibangun dengan menggunakan teknik pemrograman berorientasi objek[11].

\subsubsection{Disain Use Case Diagram}

Untuk mendapatkan gambaran mengenai sistem yang akan dibuat maka digambarkan dalam model usecase diagram seperti yang terlihat pada gambar berikut.

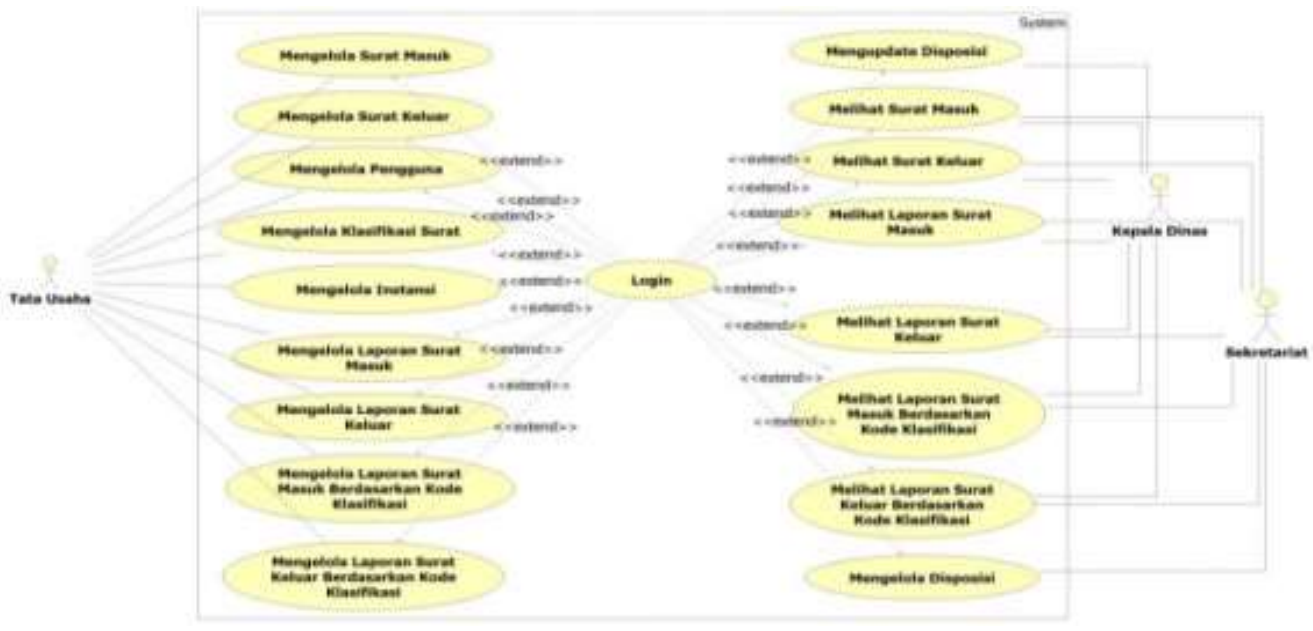

Gambar 2. Disain Use Case 
JURNAL MEDIA INFORMATIKA BUDIDARMA

Volume 4, Nomor 2, April 2020, Page 363-368

ISSN 2614-5278 (media cetak), ISSN 2548-8368 (media online)

Available Online at https://ejurnal.stmik-budidarma.ac.id/index.php/mib DOI 10.30865/mib.v4i2.2033

\subsubsection{Disain Class Diagram}

Perancangan sistem model class diagram bertujuan menggambarkan relasi-relasi antar tabel:

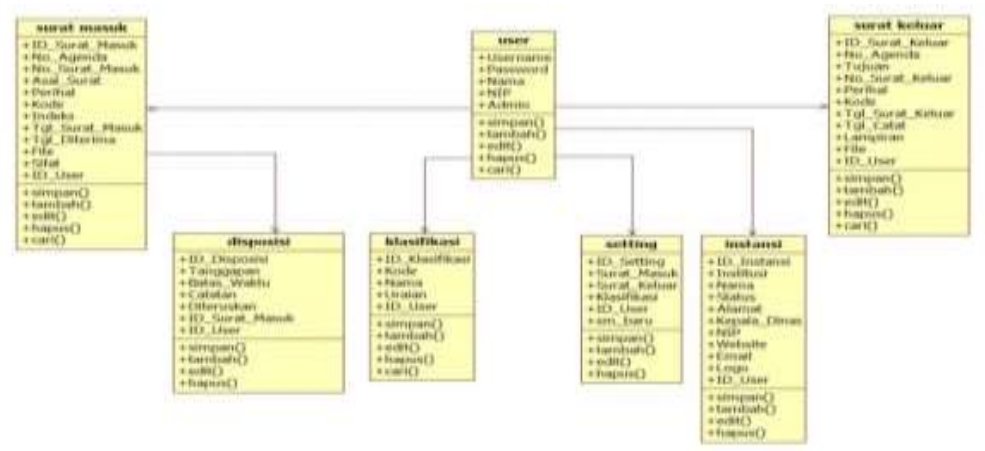

Gambar 3. Disain Class Diagram

\subsubsection{Disain Basis Data}

Perancangan tabel ini bertujuan untuk mempermudah mengetahui field-field yang dibutuhkan dalam pembuatan tabel yang berkaitan dengan sistem informasi pengarsipan surat masuk dan surat keluar

\section{A. Desain Basis Data Surat Masuk}

Basis Data surat masuk digunakan untuk menyimpan data surat masuk. Terdapat beberapa field dalam tabel surat masuk yaitu id_surat, no_agenda, no_surat, asal_surat, perihal, kode, indeks, tgl_surat, tgl_diterima, file, sifat dan id_user.

Tabel 1. Disain Basis Data Surat Masuk

\begin{tabular}{cllll}
\hline No & & Tipe Data & \multicolumn{1}{c}{ Size } & \multicolumn{1}{c}{ Ket } \\
\hline 1 & Id_surat_masuk & Varchar & 6 & Primary Key \\
2 & No_agenda & Varchar & 6 & \\
3 & No_surat_masuk & Varchar & 20 & \\
4 & Asal_surat & Varchar & 250 & \\
5 & Perihal & Mediumtext & - & \\
6 & Kode & Varchar & 30 & \\
7 & Indeks & Varchar & 30 & \\
8 & Tgl_surat_masuk & Date & - & \\
9 & Tgl_diterima & Date & - & \\
10 & File & Varchar & 250 & \\
11 & Sifat & Varchar & 250 & \\
12 & Id_user & Tinyint & 2 & \\
\hline
\end{tabular}

\section{B. Disain Basis Data Surat Keluar}

Basis Data surat masuk digunakan untuk menyimpan data surat keluar. Terdapat beberapa field dalam tabel surat keluar yaitu id_surat, no_agenda, tujuan, no_surat, perihal, kode, tgl_surat, tgl_catat, file, lampiran dan id_user.

Tabel 2. Disain Basis Data Surat Keluar

\begin{tabular}{cllll}
\hline No & & Data Type & Size & Ket \\
\hline 1 & Id_surat_keluar & Varchar & 6 & Primary \\
2 & No_agenda & Vey & \\
3 & Tujuan & Varchar & 6 & \\
4 & No_surat & Varchar & 250 & \\
5 & Perihal & Medium text & - & \\
6 & Kode & Varchar & 30 & \\
7 & Tgl_surat_keluar & Date & - & \\
8 & Tgl_catat & Date & - & \\
9 & File & Varchar & 250 & \\
10 & Lampiran & Varchar & 250 & \\
11 & Id_user & Tinyint & 2 & \\
\hline
\end{tabular}




\section{HASIL DAN PEMBAHASAN}

Sistem informasi pengarsipan surat masuk dan surat ini dibuat menggunakan bahasa pemrograman PHP (Hypertext Preprocessor) dan database MySQL (My Structure Query Language) yang digunakan untuk merancang tampilan, melakukan proses penyimpanan data dan informasi.

\subsection{Tampilan Halaman Login}

Halaman ini akan menampilkan antarmuka form login. Setiap admin harus mengisi username dan password sesuai dengan yang ada pada database, jika data yang di input sesuai dengan database maka akan masuk ke halaman utama. Sistem informasi pengarsipan surat memiliki tiga admin yaitu staf, sekretaris dan kepala badan yang memiliki hak akses masing - masing dalam mengelola data. Setiap admin harus melakukan login sebelum masuk ke halaman utama.

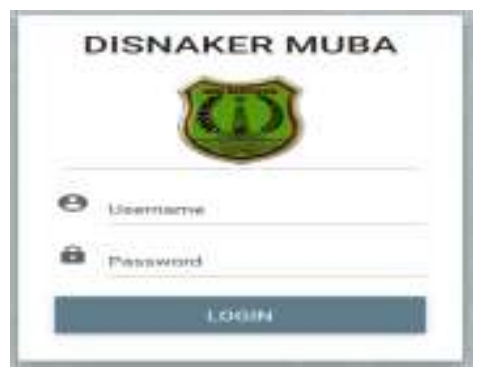

Gambar 4. Tampilan Halaman Login

\subsection{Tampilan Halaman Kelola Surat Masuk}

Tabel data surat masuk menampilkan data-data surat masuk yang tersimpan pada database. Ada beberapa tombol yaitu tambah data, edit, hapus dan disposisi seperti yang terlihat pada gambar berikut. Jika tombol tambah datadi klik maka akan tampil form input data surat. Untuk menampilkan form edit surat masuk silahkan klik tombol edit dan jika klik tombol hapus maka data surat yang ada pada baris tombol hapus tersebut data akan terhapus. Jika tombol disposisi diklik maka tampil lembar disposisi surat. Berikut adalah tampilan antarmuka lihat data surat masuk.

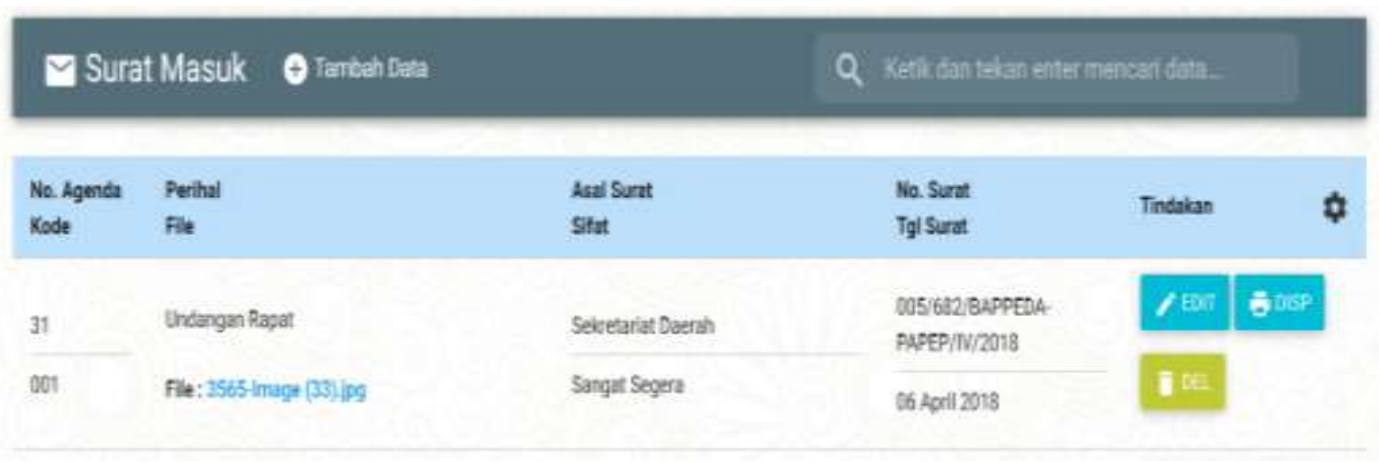

Gambar 5. Kelola Surat Masuk

\subsection{Tampilan Halaman Laporan Surat Masuk}

Form pada laporan surat masuk menampilkan data-data laporan surat masuk. Berikut adalah tampilan antarmuka lihat laporan surat masuk.

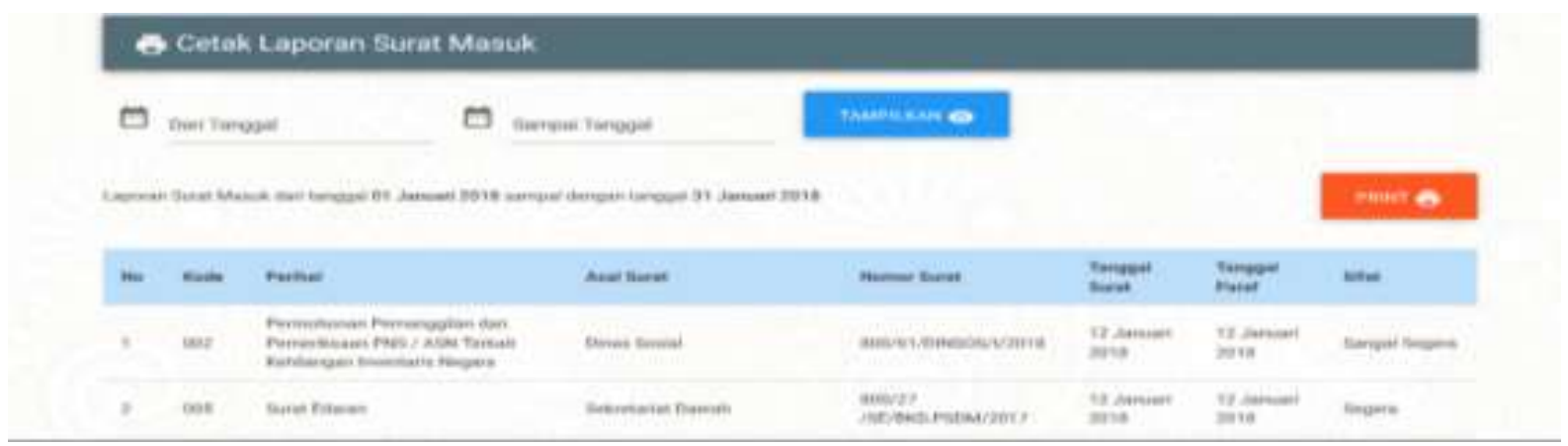

Gambar 6. Laporan Surat Masuk 


\subsection{Kelola Surat Keluar}

Tabel data surat keluar menampilkan data-data surat keluar yang tersimpan pada database. Ada beberapa tombol yaitu tambah data, edit, dan hapus seperti yang terlihat pada gambar berikut. Jika tombol tambah data di klik maka akan tampil form input data surat. Untuk menampilkan form edit surat keluar silahkan klik tombol edit dan Jika klik tombol hapus maka data surat yang ada pada baris tombol hapus tersebut data akan terhapus. Berikut adalah tampilan antarmuka lihat data surat keluar.

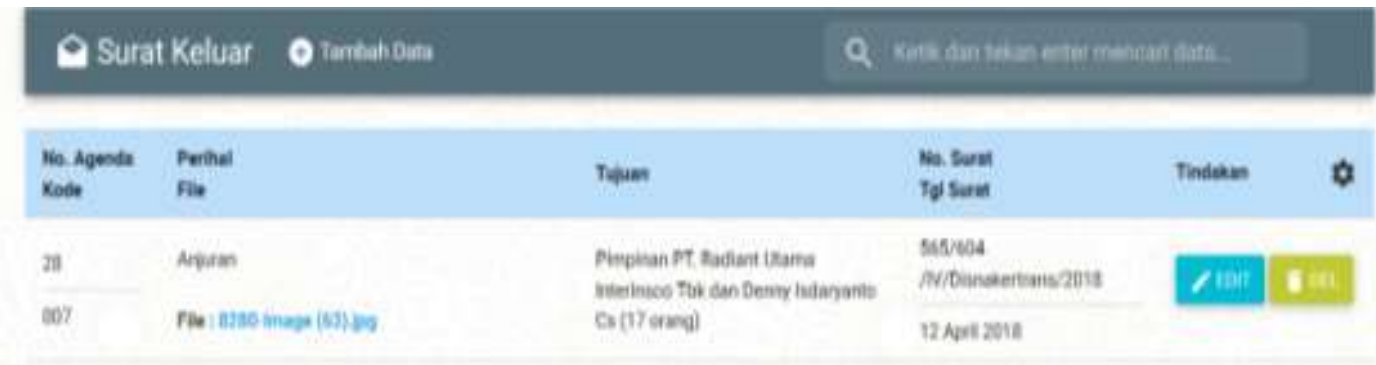

Gambar 7. Kelola Surat Keluar

\subsection{Tampilan Halaman Laporan Surat Keluar}

Form data laporan surat keluar menampilkan data-data laporan surat keluar. Berikut adalah tampilan antarmuka lihat laporan surat keluar.

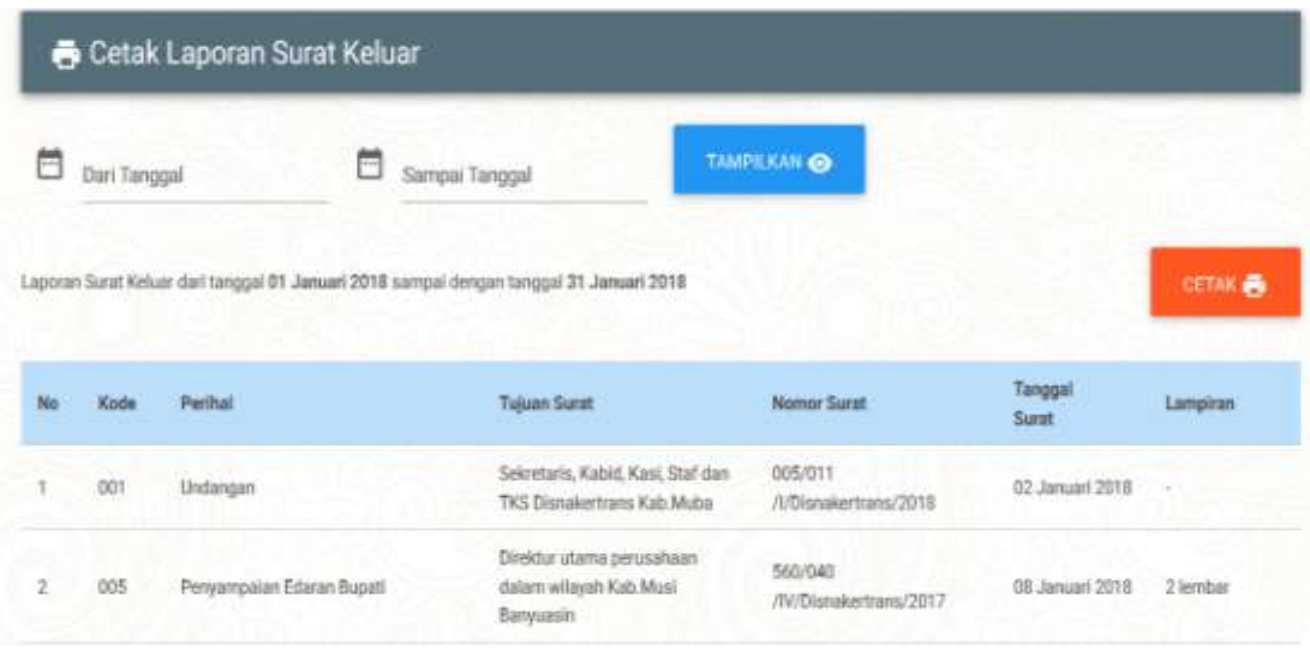

Gambar 8. Laporan Surat Keluar

\section{KESIMPULAN}

Setelah melalui tahap - tahap dalam perancangan serta implementasi dalam Sistem Informasi Pengarsipan surat pada Dinas Tenaga Kerja dan Transmigrasi Kabupaten Musi Banyuasin maka dapat diambil kesimpulan bahwa Sistem informasi pengarsipan surat ini telah berjalan sesuai perancangan yang telah dibuat. Pada sistem informasi tersebut terdapat 3 (tiga) halaman utama, yaitu halaman admin, halaman sekretariat dan halaman kepala dinas dan Sistem informasi ini memberi kemudahan kepada pegawai dalam pengolahan data surat, laporan surat dan disposisi surat yang termonitor dengan baik sehingga dapat memberikan kemudahan dalam penemuan kembali surat yang tersimpan.

\section{UCAPAN TERIMAKASIH}

Alhamdulillah, puji dan syukur kami panjatkan kepada Allah SWT yang telah melimpahkan rahmat dan karunia nya serta kesehatan kepada kita semua, sehingga jurnal ini dapat terselesaikan. Dan tak lupa juga kami berterima kasih kepada :

1. Ibu Dr. Sunda Ariana, M.Pd., M.M selaku Rektor Universitas Bina Darma.

2. Pimpinan, Staf dan Karyawan Dinas Tenaga Kerja dan Transmigrasi Kabupaten Musi Banyuasin

3. Bapak Dedy Syamsuar., Ph.D. selaku Dekan Fakultas Ilmu Komputer Universitas Bina Darma.

4. Ibu Fitriya, S.E., MBA., Ph.D. selaku Direktur DRPM Universitas Bina Darma. 
JURNAL MEDIA INFORMATIKA BUDIDARMA

Volume 4, Nomor 2, April 2020, Page 363-368

ISSN 2614-5278 (media cetak), ISSN 2548-8368 (media online)

Available Online at https://ejurnal.stmik-budidarma.ac.id/index.php/mib DOI 10.30865/mib.v4i2.2033

\section{REFERENCES}

[1] G. Farell, H. K. Saputra, dan I. Novid, "RANCANG BANGUN SISTEM INFORMASI PENGARSIPAN SURAT MENYURAT (STUDI KASUS FAKULTAS TEKNIK UNP)," J. Teknol. Inf. dan Pendidik., vol. 11, no. 5, hal. 55-62, 2018.

[2] S. Mahmuda, L. Widiastuti, dan S. Ernawati, "Sistem Informasi Pengarsipan Surat Masuk dan Surat Keluar (Studi Kasus Ma Darul Ihya Bogor),” J. Media Inform. Budi Darma, vol. 3, no. 3, hal. 225-231, 2019.

[3] G. P. Sari, J. Marzal, dan M. Mauladi, "RANCANG BANGUN SISTEM INFORMASI PERSURATAN DAN DISPOSISI ELEKTRONIK UNIVERSITAS JAMBI,” J. Sains dan Sist. Inf., vol. 1, no. 1, hal. 20-29, 2018.

[4] C. Puspasari, Durinda; Nikmah, "Effectiveness of Archive Management on Record System in National Zakat Agency in Indonesia," in 2nd Social Sciences, Humanities, and Education Conference (SoSHEC 2018), 2018, hal. 283-288.

[5] A. Simangunsong, "Sistem Informasi Pengarsipan Dokumen Berbasis Web," J. Matrik Penusa, vol. 2, no. 1, hal. 11$19,2018$.

[6] W. Chandra dan R. Amalia, "SISTEM INFORMASI PEMESANAN KAMAR MESS PT. KAI PERSERO DIVRE III SUMATERA SELATAN,” CESS(Journal Comput. Eng. Syst. Sci., vol. 4, no. 1, hal. 88-93, 2019.

[7] H. T. Sitohang, "SISTEM INFORMASI PENGAGENDAAN SURAT BERBASIS WEB PADA PENGADILAN TINGGI MEDAN," J. Inform. Pelita Nusant., vol. 3, no. 1, hal. 6-9, 2018.

[8] N. Fatimah dan Y. Elmasari, "PERANCANGAN SISTEM INFORMASI PERPUSTAKAAN BERBASIS WEB UNTUK SMA ISLAM SUNAN GUNUNG JATI," JurnalIlmiah Penelit. dan Pembelajaran Inform., vol. 3, no. 2, hal. 130-137, 2018.

[9] N. Huda, "SISTEM INFORMASI WISATA SUMATERA SELATAN BERBASIS MOBILE," J. Tek. Inform. Politek. Sekayu, vol. 7, no. 2, hal. 51-56, 2017.

[10] I. Elyana, I. Kholil, dan F. E. Schaduw, "RANCANG BANGUN SISTEM INFORMASI MANAJEMEN DISPOSISI SURAT MENYURAT DENGAN MENGGUNAKAN MODEL RAD (RAPID APPLICATION DEVELOPMENT)," J. Ris. Inform., vol. 1, no. 2, 2019.

[11] A. Sopandi, "Design And Development Of Correspondence Management Application Based On Android," in 7th International Conference on Cyber and IT Service Management (CITSM), 2019, hal. 1-6. 